\title{
Correction to: Ultraviolet absorbance of Sphagnum magellanicum, S. fallax and S. fuscum extracts with seasonal and species-specific variation
}

\author{
$J_{\text {. Tienaho }}{ }^{1} \cdot$ N. Silvan $^{1} \cdot$ R. Muilu-Mäkelä ${ }^{1} \cdot$ P. Kilpeläinen ${ }^{2} \cdot$ E. Poikulainen $^{3} \cdot$ T. Sarjala $^{1}$
}

Published online: 15 April 2021

(c) European Photochemistry Association,European Society for Photobiology 2021

\section{Correction to: \\ Photochemical \& Photobiological Sciences \\ (2021) 20:379-389 \\ https://doi.org/10.1007/s43630-021-00026-w}

The publication of this article unfortunately contained a mistake. In Figs. 4 and 5, y-axis title is wrongly written as "Peak area" correct it should be "Abundance". The corrected Figs. 4 and 5 are given below:

The original article has been corrected.

The original article can be found online at https://doi.org/10.1007/ s43630-021-00026-w.

\section{J. Tienaho}

jenni.tienaho@luke.fi

1 Production Systems Unit, Biomass Characterization and Properties Group, Natural Resources Institute Finland (Luke), Kaironiementie 15, 39700 Parkano, Finland

2 Production Systems Unit, Biorefinery and Bioproducts Group, Natural Resources Institute Finland (Luke), Tietotie 2, 02150 Espoo, Finland

3 Faculty of Natural Sciences and Engineering, Tampere University, Korkeakoulunkatu 8, 33101 Tampere, Finland 
Fig. 4 The gas chromatogram of $S$. fallax methanol extract. All the chromatograms can be found from the supplementary material and they were similar for all species

Fig. 5 The gas chromatogram of S. fallax alkali extract. All the chromatograms can be found from the supplementary material and they were similar for all species
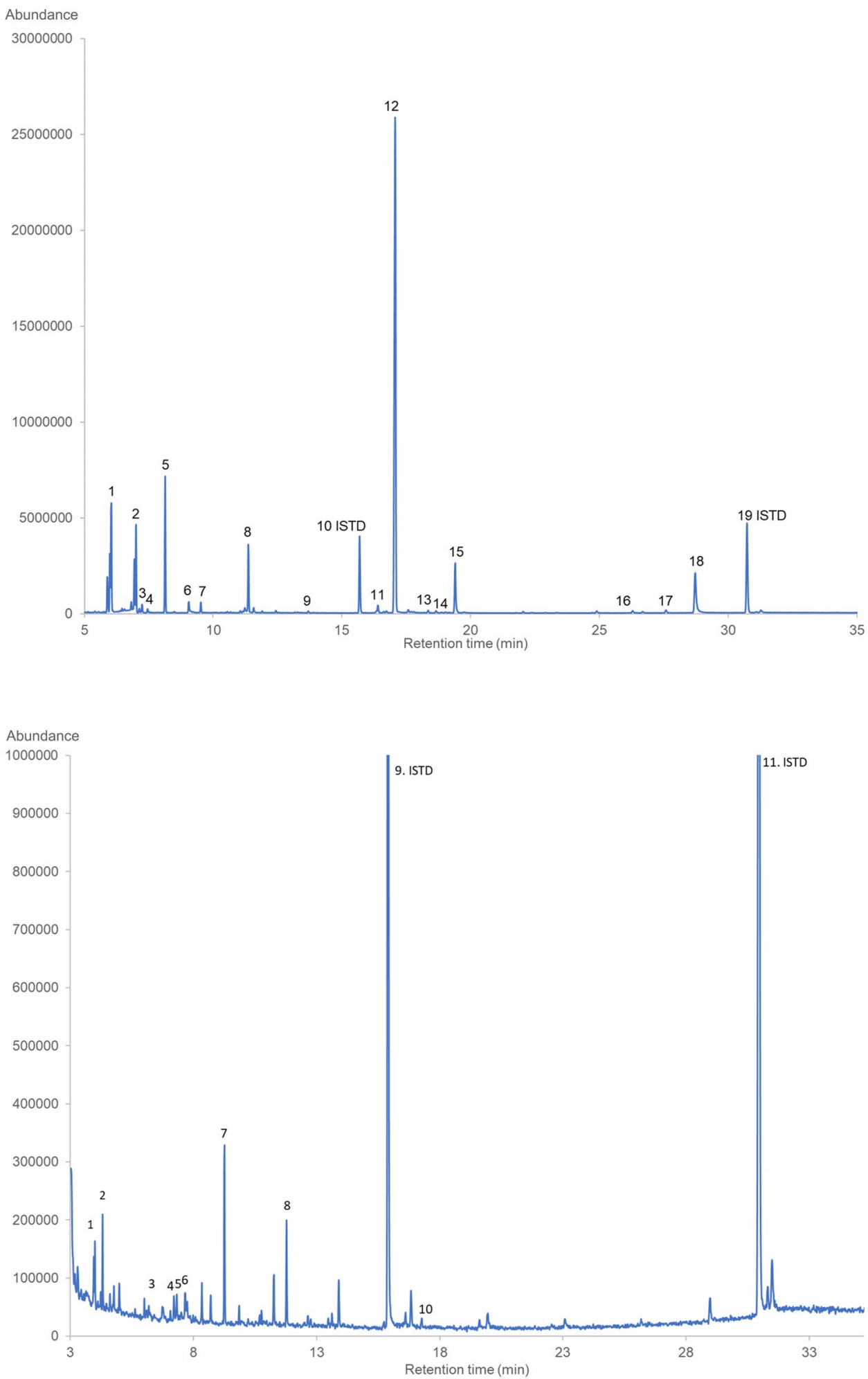